\title{
Severe limitations of the poietic individual mind
}

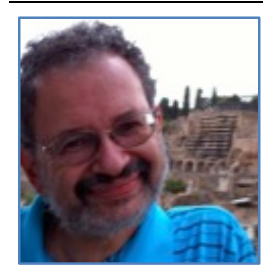

Eugene Matusov

University of Delaware, USA

\section{Abstract}

Review of the 2011 book Thinking, fast and slow by Daniel Kahneman published by New York: Farrar, Straus and Giroux (ISBN: 9780374533557; 499pp.)

$\cos 0380$

\author{
The better a person understands his/her own \\ determinism (his/her own objectness), the closer \\ he/she comes to understanding and realization of \\ his/her own genuine freedom. (Bakhtin, 2002, vol. 6, p. \\ 398 (translation from Russian is mine).
}

Daniel Kahneman, an Israeli cognitivist psychologist and a Nobel Prize winner in Economics in 2002, delivers bad news for the humanity. Our human individual mind makes very poor judgments. But even more, not only we are cognitively deficient and are unaware of these deficiencies but we rarely change our judgments even when we have learned about these deficiencies. According to Kahneman, who worked closely with another famous American cognitive psychologist Amos Tversky, our individual mind consists of two systems. System\#1 involves a mostly invisible intuitive inductive uncritical mind based on pattern recognition, association making, making consistent coherent stories, simplifying and so on. System\#2 involves mostly familiar deductive, logical, deliberate, reason- and argument-based, critical, calculative, rational mind. Through various clever lab and natural experiments and personal stories. Kahneman convincingly demonstrates how often the quick System\#1 makes judgments and decisions instead of the slow System\#2. But even when System\#2 is activated, more often than not, it uncritically swallows the data, provided by System\#1. In itself, it may not have been necessary bad, if only System\#1 had been accurate and smart - the problem is that it is not the case, according to the intensive empirical evidence provided by the author. People's mind is much less self-conscious about its own work, less rational, and more susceptive to fallacies and manipulation. In this book review, I, as a dialogic educator and researcher, want to share my excitement and appreciation as well as critique of this wonderful new book.

Let me share a few of my favorite examples from the book. The most striking evidence for me of how System\#1 tacitly guides our behavior is a case of so-called "priming." The psychologist John Bargh and his collaborators asked undergraduate 18-22-old students at New York University to assemble sentences from a set of 5 given words. In the experimental group of the students, the word sets included words associated with elderly such as "Florida," "forgetful," "bald," "gray," or "wrinkle." The control group did not have words associated with elderly. After this task, the research participants were asked to go down 
the hall to continue the experiments. However, the true focus of the researchers was on measuring the time for the participants to get across the hall. The young participants from the experimental group walked significantly slower through the hall than the participants from the control group. Kahneman explains that first, System\#1 tacitly triggered thoughts and associations about old ages, which then primed a behavior, walking slowly, which is associated with old age. Both stages of the priming occur without any awareness of the participants. Interestingly, as the cognitive researchers showed, the effect can be reversed if the participants developed negative attitude to elderly - they would walk faster than the control group. The tacit System\#1 can be easily manipulated exactly because its work is not under control of the actor.

My other favorite case about the faulty System\#1 involves the author's experiments about fictitious lady named Linda,

Linda is thirty-one years old, single, outspoken, and very bright. She majored in philosophy. As a student, she was deeply concerned with issues of discrimination and social justice, and also participated in antinuclear demonstrations (p. 156).

Graduate students were presented with the question, what is more probable: Linda is a bank teller or Linda is a bank teller who actively participates in the feminist movement. Ninety percent of the research participants chose the latter answer, despite the "obvious" fact that active feminist bank tellers are a subset of the total bank tellers pool. A subset of a pool automatically reduces the probability, regardless of a description of a particular case. Kahneman argues that in this case, the fast institutive System\#1 tacitly replaces the presented question about probability with a question about representativeness: based on Linda's description, she better matches to an active feminist, who happens to be a bank teller, than to a generic bank teller. As Kahneman convincingly demonstrates, System\#1 is notoriously bad about probabilistic judgments. In contrast to visual illusions, awareness of the cognitive fallacies caused by System\#1, does not necessarily help to correct them.

So, what should we do to address cognitive fallacies caused by the fast intuitive tacit System\#1 that often lets us jump to wrong conclusions? As Kahneman points out, mere awareness of these fallacies is not very helpful. The author proposes using special formal procedures and/or replacing human judgments with objective formulae. For example, Kahneman recommends employers, who seek to hire new employees, to develop no more than 6 independent factors that define the success of the job, operationalize each of these factors with 2-3 interview questions, and rate each job candidate on the questions using 5point scale, trying to make sure that rating on one question does not influence rating on another question. Than a simple formula should be developed adding all the rates that will allow to rank the candidates. The employer must stick to the result of the ranking, resisting any temptations to use his or her holistic judgment because the latter will be shaped by the cognitive and perceptual fallacies by System\#1. The author goes even so far to suggest that a simple formula of the frequency of sexual intercourse minus the frequency of marital disputes can predict more accurately the marriage stability or divorce rather than any clinical judgment by a marital expert. He believes that the increasing proliferation of the objective formulae based on research evidence (i.e., "evidence-based practice") will improve the practices by eliminating the subjective human judgment based on cognitive fallacies of System\#1 and, thus, will make a victory of System\#2 (rational objective calculation) over System\#1 (pattern recognition) possible.

To the author's credit, he provides self-criticism to his cognitivist research and argumentation. He admits that his research focuses on documentation of cognitive fallacies rather than to study successes of the System\#1, which might have skewed his conclusions. Also, the author admits that he has been predominately interested in human judgments involving so-called "low-validity practices." Low-validity 
practices involve a high degree of probability and/or lack of any regularity rule. Kahneman's research collaboration with Gary Klein, another reknown cognitivist psychologist and a scholarly opponent of Kahneman, helps to explore limitations of Kahneman's research, argumentation, and conclusions. Klein has found System\#1 to be much more powerful, successful, and useful. In contrast to Kahneman, Klein has studied human intuitive expert judgments in high-validity practices with immediate feedback and high deterministic regularities like firefighting or chess playing. Kahneman agrees that in these "high-validity practices," human intuitive expert judgment, based on pattern recognition, grounded in the participant's extensive experience, can be very accurate and valuable. However, as chess playing shows, smart computers (and smart programs) can outsmart human pattern recognition and thus human intuitive expert judgment.

Throughout his book, Daniel Kahneman discusses hostile reception of his research, argumentation, and conclusions. He points out that in a part, this hostility comes from our System\#2, who has difficulty to come to terms that it is not always or even not much in the driving seat of the mind. Many critics accuse Kahneman of being mechanical, rigid, non-contextual, and so on. In my authorial judgment (sic!), this critique is both unfair and fair. I judge it unfair because I agree with cognitivist psychologist Kahneman that our mind can function like a smart machine, based on a pattern recognition, and also it has limitations and fallacies, worth of studying. Recent exciting advances in smart machines based on pattern-recognition, complexity, and self-organization - such as chess playing, voice recognition, writing recognition, self-driving cars, and so on - have left no doubts that smart machines can outperform human intuitive and rational expert judgment. Furthermore, I agree with the author that formulae and smart machines should replace human intuitive expert judgment whenever it is possible. My argument in agreement with Kahneman is based not only on effectiveness, accuracy, fallacy-free, and efficiency, as Kahneman convincingly argues, but also on a moral argument that this labor and work (cf. Arendt, 1958) may not necessary be human endeavor in the first place.

This brings me to my critique of Kahneman. I argue that his mechanistic vision of human mind is based on mechanistic practices (both low and high validity practices that he considered), in which this human mind operates. Aristotle named these mechanistic practices as "poiesis." In poiesis, the goal, the definition of success, and the definition of the quality of the activity pre-exists and is predefined explicitly or implicitly before the activity takes place. In contrast to poiesis, there is "praxis", defined by Aristotle as practice, in which the goal, the definition of success, the definition of problem, and the definition of the quality (i.e., values) emerge and are negotiated in the practice itself. I argue that many cognitivist psychologists like Kahneman, Tversky, and Klein have studied mind in poietic practices. It is no surprise that in many (if not all!) Kahneman's examples and experiments, the goal, success, and quality of the activities were predefined or could be predefined in advance. If this is the case, I believe that in poiesis-like practices, human mind can be viewed as an imperfect smart machine, can be modeled by a smart machine, can be improved by a better formula and smart machine, and, thus, can be legitimately replaced by a smart machine as more accurate, reliable, effective, and efficient, regardless of how upsetting it may sound for us, humans.

While highly appreciating Kahneman's innovative approaches to study human mind and important consequential findings, I argue that the human nature cannot be reduced to predictable outcomes of behavior, judgment, and action. Boesch argued that "a main trait of human reality is to transcend itself" (1993, p. 15). This suggests that the human nature reveals itself not when human behavior, action, and judgment are governed by System\#1 (pattern recognition) or System\#2 (rational objective calculations), so nicely studied and described by Kahneman, but when humans transcend these systems, using these systems as the building material for this transcendence. Thus, patternless outliers, rather than statistically 
significant patterns, should be studied to reveal this transcending essence of the human nature (Gladwell, 2008). The outliers often creatively redefine the situation, the purpose of the activity, the normative relations in which they find themselves, transforming the poiesis of the psychological experiments into praxis. The issue of desirability becomes for us of how we can promote an authorial judgment, which is responsible i.e., answerable to other people and the actor him/herself, - rather than how we can subordinate the System\#1 (pattern recognition) to System\#2 (rational objective calculation). The authorial responsible judgment does not annihilate nor does it put aside System\#1 and System\#2 - pattern recognition and rational calculations - but, it rather uses them as the material for their transcendence. This is especially important in education. Let's consider the following example.

Matusov (2015) describes a case, in which an educator, named in his article as Mr. Jim, faced an important educational dilemma. Mr. Jim worked in an afterschool program with Latino/a children at a local Latin-American Center in the US in the early 2000s. He organized an activity, in which 7-14 years old children had an opportunity to create their "digital stories." Mr. Jim got two expensive digital cameras from a local state university that the children, who wanted to participate in the activity, could borrow for a day or two to shoot a video of their choice. Then, they edited their raw footage and added narration and music through Mr. Jim's guidance and peer mutual help. Mr. Jim designed an online prototype of YouTube (it was before video sharing was available on the Internet), the Center's children, staff, and parents could rate the children's videos and make comments on them. Since, there were more children who wanted to participate in the activity than the cameras, Mr. Jim developed a waiting list. Pedro, a 12-year old Mexican boy, signed for the activity. Pedro had very negative reputation at the Center. He was known to the Center children and staff as a thief. He was caught twice by the police for shoplifting and was suspected in stealing a cellular phone from the Center. He had countless suspensions and detentions from his school and he had problems with his behavior at the Center. Many children at the Center did not like him because of his stealing and involvement in fights. When his turn came to borrow an expensive digital camera, not only the Center staff but also many children objected because they were sure that Pedro would simply steal the $\$ 1000$-worth camera. Pedro also expected that he would not get the camera and started his objection arguments in a whining and increasingly aggressive tone. To surprise of all, Mr. Jim offered a camera to Pedro. Pedro could not believe in what happened and tried to make sense of it. He asked Mr. Jim if he had many cameras. Mr. Jim said that he had only two. Pedro asked how expensive the cameras were. Mr. Jim replied that each costed $\$ 1000$. Pedro asked what would happen if a camera disappeared. Mr. Jim replied that the Center would become a less exciting place, the university would probably stop giving money to support the Center's exciting activities. Then Pedro directly asked Mr. Jim of why he was trusting the expensive digital camera to him. Mr. Jim replied because he was next and because he wanted to make a digital story. Pedro took the camera. Next day, he was suspended from the Center for a fight for a few days. However, he asked his father, who had three jobs, to come to the Center after his third job to return the camera on time. Pedro's digital story about his drug infested neighborhood was the winner - it had the highest rating on the videosharing site designed by Mr. Jim.

In argument with Mr. Jim, Mr. David, another instructor at the Center, provided a very good rational evidence-based argument guided by System\#1 and System\#2 of why Pedro should not be trusted with an expensive digital camera. The risk was high. Mr. Jim did not have much rational, objective, evidence-based counter-argument to offer. It was not a case that Mr. Jim had known something about Pedro that Mr. David or the rest of the community had not known. It was not a case that Mr. Jim calculated Pedro better than the rest (Bakhtin, 1999), foreseeing that his trusting defenseless offer of the expensive camera would transform Pedro's vile nature through this random act of kindness. No. Although Mr. Jim was very glad that Pedro returned the expensive camera back and won the digital story competition with his brilliant socially-charged video, it was not his goal either. What was it? 


\section{Severe limitations of the poietic individual mind}

Eugene Matusov

At the time, during the events, Mr. Jim did not know what was the goal of his trusting offer to Pedro. It took several years for him to fully realize and articulate it. Mr. Jim realized that he wanted to disrupt the toxic careless environment and predictable dysfunctional social relations in which Pedro had been trapped back then, in order to create a space for Pedro's authorial responsible action (and judgment). This authorial responsible action might or might not involve returning camera. For example, Pedro might have decided to sell it in order to buy medicine and toys for his sick younger brother, unilaterally prioritizing the acute needs of his family over educational and entertaining needs of the Center. This arguably could also have been an authorial responsible action but its responsibility unilaterally prioritizing family over the Community Center, would have been contested. The dialogue, initiated by Pedro, between Pedro and Mr. Jim about the meaning of his action was very important for creating this space for authorial responsible action because with a high probability this dialogue continued for Pedro internally and externally perhaps in his family. Citing famous German poet of the XIX century Goethe, Viktor Frankl argued,

If we take man as he is, we make him worse, but if we take man as he should be, we make him capable of becoming what he can be ... So if you don't recognize a young man's will to meaning, man's search for meaning, you make him worse: you make him dull, you make him frustrated. While if you presuppose in this man, there must be a spark for meaning. Let's presuppose it and then you will elicit it from him, you will make him capable of becoming what he in principle is capable of becoming (Frankl, 1972,).

Again, the issue is not to calculate Pedro into a desirable action or an attitude, but rather to create an opportunity for a human-to-human encounter be able to occur (Bakhtin, 1999; Buber, 2000),

The encounter/meeting is the ultimate opportunity to hear yourself in the other. This other can be a physical interlocutor or it can be an encounter with a text or with some phenomenon of culture, which forces me to make that very effort. The encounter/meeting, which I am talking about, is that what presupposes my great effort to encounter the other who is not overlapping with me (i.e., opaque to me), but who is interesting for me. [This meeting generates] a point of puzzlement/surprise and at the same time it is a point of some kind of unusual joy of discovery of myself in the [other] unexpected for me. This is as if [the other] talks about something that is deeply intuitively clear to me. And at the same time, [the other] creates the space, in which these deep intuitions of mine begin to live and begin the fireworks of my own creative thinking ... [The other] capture[s]/hook[s] something in me, which is essential about me. To "capture/ hook" something in me, means to provoke, spark, self-actualize, and initiate some kind of my own activity. And this situation of the encounter/meeting that I am describing here is, as a matter of fact, an educational situation. The genuine education unavoidably involves an element of provocation.

What is important for me, as a teacher, is that my encounter with the students is the space of my own personal self-growth, my own self-actualization. The encounter with my students is the process of my own selfmaking/self-creation/self-becoming and, thus, my own self-education (originally in Lobok, 2014; cited in Matusov \& Marjanovic-Shane, 2015, p. 216).

In case of Mr. Jim and Pedro, this encounter occurred, making both of them outliers of the given past relations. However, this encounter is not and never can be guaranteed. Arguably, the purpose of education (among some others) is to create possibilities for such human-to-human encounters. An educator cannot design an encounter but only favorable conditions for it.

Kahneman can be wrong because he equates the human mind-in-poiesis, i.e., "taking man as he is" (cf. Frankl's quote above), with the human per se. Human mind in praxis-like practices, where goals, problems, values, successes, qualities emerge, are defined by and negotiated with the immediate and remote participants, may not be studied and approached in the same way Kahneman has studied and 
approached mind-in-poiesis because an observed phenomenon does not exist independently of the observer, who is just another participant in defining and negotiation of the goals, values, problems, and so on (this is just one of many reasons, see other reasons here: Matusov \& Marjanovic-Shane, 2016, in pressa). For example, judgement of a pedagogical success is always contested and is in the eye of the beholder. Thus, Sigmund Ongstad (2007) presented an interesting, but sad, story illustrating how mainstream school does not appreciate and care about students engaging in Big Dialogue about ideas and testing limits of knowledge, if not actively discourages them,

The following task was given as one in a set at the official national exam in 'Norwegian' for all upper secondary schools (high schools) in 1973 in Norway, 'The number of youngsters who marry already in their teen ages has increased heavily the last years. There are especially many girls who marry that early. What can be the causes for this development, and what is your view upon that so many marry so young?' Later the same year a class at a local school got the same task. However, one of the students contested the very premise for the task and wrote, as his assignment, a harsh critique of the whole task, arguing why the premise is invalid. The local lecturer gave him a bad mark (for not having answered the given task). The student then contacted the Central Statistical Office, who could confirm that he was actually right. The premise was not valid. He then approached the teacher and the Norwegian department of Education again, without result. He even challenged the school's headmaster, who was a MTE teacher as well, in the hope that this 'sensible man' would support his claim. However, neither the headmaster nor the Norwegian department of Education would admit any mistake. The task had even been given at the national exam the same year and had not caused problems. And one crucial argument was: You are bristling up against the task instead of trying to come to grips with the problem (Retold in English based on an article in Aftenposten (newspaper), Oslo October 1973 by Sigmund Onstad).

This reminds us of a confrontation between Soviet psychologist Luria and illiterate adult Uzbeks, who rejected the premises of Luria's syllogisms in his famous experiments in Central Asia in the early 1930s (Luria, 1976; Matusov \& St. Julien, 2004; Scribner, 1977). Authorial judgements by outliers can be judged by other outliers, whose judgment will have to be also authorial, thus, contested and not objective because the purpose, the definition of quality, and the criteria for judgment emerge in the judgment itself and do not pre-exist it as it is in school tests and Kahneman's and Luria's psychological experiments.

Another, but related, limitation of Kahneman's research ontology is his interest in isolated, selfcontained, monologic mind. Again, this interest may be legitimate in poiesis-like practices divorced from other aspects of human life. However, in praxis-like activities, where new meanings, new goals, new quality, new judgment criterions emerge, mind should be viewed as connected, transactional, and dialogic. In praxis-like activities, meaning emerges not as a pattern or rational calculation but as a serious answer to a genuine, information-seeking question asked primary by the other and secondary by the self (Matusov \& Marjanovic-Shane, 2016, in press-b). Thus, it is important to point out the limitations of the cognitive studies of human mind that can never be reduced to System\#1 or System\#2. We need a new science of human mind as authorial dialogic outliers, moving away from poiesis-like objective voiceless methodologies (cf. Bakhtin, 1986, who made a similar call).

Psychology of judgment is viewed by Kahneman either as a deviation from the classical rationalism or as an illegitimate shortcut to the classical rationalism. These psychological deviations and shortcuts have their own regularities that cognitivist psychologists, like Kahneman, study by using a big number of subjects. Classical rationalists view people as perfect, or, at least, desired machines. Cognitivist psychologists view humans as imperfect machines, although not without their own heuristic advantages in "high-validity" practices. In both cases, humans are given and calculable (at least in a statistical sense of the big number). My criticism here is not that the classical rationalism and cognitive psychologism are wrong but rather that

Dialogic Pedagogy: An International Online Journal | http://dpj.pitt.edu

DOI: 10.5195/dpj.2017.178 | Vol. 5 (2017) 
their truth is limited and they do not know and do not seek to know their own limits. I agree with classical rationalists and cognitive psychologists, like Kahneman, Tversky, and Klein, that humans are and can be both perfect and imperfect machines in their thinking and acting. This makes their studies of humans as imperfect predictable calculable machines very useful and consequential. However, I disagree with Kahneman's approach to mind reducing humans to perfect or imperfect predictable calculable machines and defining the human nature as such. I see the most important usefulness of studying humans as (im)perfect machines in helping us stop acting like rational or irrational machines when we wish so and, thus, to claim our non-machine-like, unpredictable, incalculable, dialogic humanity. I think it is extremely useful to consider humans as being both (im)perfect machines and as authorial dialogic agencies. In this sense, my view of humans is unapologetically dualistic.

\section{Acknowledgement}

I want to thank my colleagues Bob Hampel and Ana Marjanovic-Shane for their critical feedback and suggestions for improvements on my earlier drafts of the review. Also, I want to thank Mikhail Gradovski for encouraging writing the book review and Ricardo Freire for suggesting reading this book.

\section{References}

Arendt, H. (1958). The human condition. Chicago: University of Chicago Press.

Bakhtin, M. M. (1986). Speech genres and other late essays. Austin: University of Texas Press.

Bakhtin, M. M. (1999). Problems of Dostoevsky's poetics. Minneapolis: University of Minnesota Press.

Boesch, E. E. (1993). The sound of the violin. The Quarterly Newsletter of the Laboratory of Comparative Human Cognition, 15(1), 6-16.

Buber, M. (2000). I and Thou (R. G. Smith, Trans. 1st Scribner Classics ed.). New York: Scribner.

Gladwell, M. (2008). Outliers: The story of success (1st ed.). New York: Little Brown and Co.

Frankl, V. (1972).Frankl's speech, 'Why to believe in others?'. Retrieved from http://www.ted.com/talks/viktor_frankl_youth_in_search_of_meaning

Lobok, A. (2014). Education/obrazovanie as an experience of an encounter. Dialogic Pedagogy: An International Online Journal, 2, S1-S5. Retrieved from http://dpj.pitt.edu/ojs/index.php/dpj1/article/view/84 doi:10.5195/dpj.2014.84

Luria, A. R. (1976). Cognitive development, its cultural and social foundations. Cambridge, MA: Harvard University Press.

Matusov, E. (2015). Four Ages of our relationship with the Reality: An educationalist perspective. Educational Philosophy and Theory, 47(1), 61-83. doi: 10.1080/00131857.2013.860369

Matusov, E., \& Marjanovic-Shane, A. (2015). Typology of critical dialogue and power relations in Democratic Dialogic Education. In K. Jezierska \& L. Koczanowicz (Eds.), Democracy in dialogue, dialogue in democracy (pp. 211-229). Farnham, UK: Ashgate Publishing Ltd.

Matusov, E., \& Marjanovic-Shane, A. (2016, in press-a). Dialogic authorial approach to creativity in education: Transforming a deadly homework into a creative activity. In V. P. Glăveanu (Ed.), The 
Palgrave Handbook of Creativity and Culture Research. Hampshire, UK: Palgrave Macmillan Publishers Ltd.

Matusov, E., \& Marjanovic-Shane, A. (2016, in press-b). Many faces of the concept of culture (and education). Culture \& Pcychology, 1-28. doi: 10.1177/1354067X16655460

Matusov, E., \& St. Julien, J. (2004). Print literacy as oppression: Cases of bureaucratic, colonial, totalitarian literacies and their implications for schooling. TEXT: International Journal, 24(2), 197244.

Ongstad, S. (2007). Argument(s) and/as utterances, genres and context. Paper presented at the Argumentation in (con)text. January 2007. University of Bergen, Norway: Bergen.

Scribner, S. (1977). Modes of thinking and ways of speaking: Culture and logic reconsidered. In P. N. Johnson-Laird \& P. C. Wason (Eds.), Thinking (pp. 483-500). Cambridge, UK: Cambridge University Press.

\section{(c)) EY}

New articles in this journal are licensed under a Creative Commons Attribution 4.0 United States License.

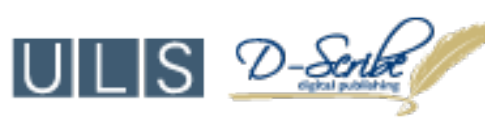

This journal is published by the University Library System, University of Pittsburgh as part of its D-Scribe Digital Publishing Program and is cosponsored by the University of Pittsburgh Press. 